\title{
Industrial Engineering: Why students come and what makes them stay?
}

\author{
Randa L. Shehab ${ }^{1}$, Teri Reed Rhoads ${ }^{1,2}$, and Teri J. Murphy ${ }^{3}$ \\ School of Industrial Engineering ${ }^{1}$, College of Engineering ${ }^{2}$, \\ Department of Mathematics ${ }^{3}$, the University of Oklahoma
}

\begin{abstract}
The relative anonymity of industrial engineering may be a significant reason for the slow growth of the discipline and the relatively low enrollment in industrial engineering academic programs. In order to inform industrial engineering (IE) degree programs of factors that help increase both enrollment and graduation rates, this paper summarizes the outcomes of IE student interviews regarding what drew them to the industrial engineering program at the University of Oklahoma and what encouraged them to stay. Out of 45 IE students interviewed, 79 total comments (comprising 13 classifications) were identified addressing recruiting and only 27 comments (across 5 classifications) addressed retention. The majority of students $(53 \%)$ reported that the nature of the degree was a critical factor in choosing IE as a major. This demonstrates the importance of informing students about IE as a career option. For retention, it appeared that student-faculty interaction had the strongest impact, as reported by $29 \%$ of the sample. While this factor may be more difficult to implement, it was critical for students in our sample to have interaction with the faculty outside of the classroom and to feel that the faculty were interested in the students' futures.
\end{abstract}

Introduction

The number of engineering graduates from 1970 to 2000 has increased considerably in spite of the periodic influence of economic trends. Chemical Engineering has experienced a growth of $56 \%$ in degrees conferred, with Electrical Engineering, Civil Engineering, and Mechanical Engineering following closely behind ( $44 \%, 41 \%$, and $41 \%$, respectively). Industrial Engineering, however, has experienced much more moderate growth in the number of degrees conferred (up only $23 \%$ ) and lags behind the other disciplines considerably in the actual number of graduates ${ }^{1}$. In fact, Engineering Trends ${ }^{2}$ reports that the relative enrollment (proportion of all engineering full-time enrollment) in Industrial Engineering has not changed from 1980 through 2002 nor is it predicted to increase in the near future. And the Engineering Workforce Commission reports that Industrial Engineering has the lowest freshman full-time enrollment of all the engineering disciplines as of Fall $2001^{3}$.

Thus, it is not surprising that engineering freshman polled about the different engineering disciplines invariably seem to have a concept of what the "traditional" engineering disciplines (i.e. civil, mechanical, electrical) do. However, the question, "Who knows what industrial engineers do?" is met mostly with blank stares. Herein lies a problem attracting students to the field of industrial engineering. This paper reports data that reflect student comments regarding what drew them to the industrial engineering program at the University of Oklahoma and what 
encouraged them to stay. The themes extracted from these data can be used to help increase both enrollment and graduation in industrial engineering degree programs.

Background

Although the number of engineering graduates has steadily increased over the last several decades, the long-term national projections are for a shortage of science and engineering professionals. The need for national security and strengthening the national economy can only be accomplished with a strong technical workforce. However, the number of scientific and engineering workers is projected to fall short of anticipated national needs due to impending retirement of the current science and engineering workforce, the slow growth in undergraduate and graduate student enrollments, particularly that of US citizens, and the global competition for science and engineering workers ${ }^{4,5}$.

In an attempt to head off this projected shortage, attention has focused on the academic process, trying to understand how to make engineering more attractive to enrolling freshman and how to encourage persistence through to graduation. Most studies discuss engineering collectively, without individual treatment of the different discipline tracts. However, the individual studies within an engineering student population tend to reflect common themes centered on recruitment to the degree program (and ultimately the profession) and retention through to graduation.

An obvious approach to increasing participation in the engineering workforce is to recruit more students to engineering degree programs. One of the obstacles that must be overcome for successful recruitment is that of the "engineer's" image. Edward reports that pre-college students typically perceive engineering as practical, yet unglamorous ${ }^{6}$. This image blankets all engineering disciplines, and potentially serves to dissuade pre-college students from choosing an engineering profession. Industrial engineering suffers an additional burden of being labeled by some within the engineering community as "imaginary engineering," suggesting that industrial engineering is not really engineering or that it is easier than other engineering disciplines. Industrial engineering students report that this is indicative of the lack of understanding about what the discipline represents and have suggested that industrial engineering is "invisible"7. Many academic institutions have recruitment programs designed to inform students about opportunities in engineering. For example, numerous Universities use summer programs to introduce engineering to middle school and high school students and research has shown that students are making the decision to pursue engineering as early as the $7^{\text {th }}$ and $8^{\text {th }}$ grades ${ }^{8}$. Many recruitment programs are designed to target underrepresented student populations. However, informing students of the engineering profession may not be sufficient to attract them to an engineering degree program. According to the National Science Board's report The Science and Engineering Workforce: Realizing America's Potential, affordability is one of the primary obstacles to students selecting (and ultimately completing) a science and engineering degree program. The report strongly recommends that the federal government provide financial assistance to well-qualified students interested in a science or engineering career ${ }^{5}$.

Whereas recruitment might seem like half of the battle, the issue of retention in engineering is overwhelming. Nationally, less than $50 \%$ of students initially enrolling in an engineering degree program receive bachelor's degrees. These figures are even worse for underrepresented student 
groups. The largest attrition occurs during the first year of college, with attrition rates decreasing as students approach graduation.

The issue of retention in engineering education has been empirically studied and there are strong themes throughout the reports of students who struggle in or leave an engineering program. Lack of preparedness, particularly in high school chemistry and mathematics, is a very strong factor that influences students' ability to persevere in engineering 9, 10,11. Anderson-Rowland found a strong relationship between attrition from engineering during the first year in college and earning a poor grade in the first college mathematics course ${ }^{8}$. Edward cites Elton ${ }^{12}$ who refers to the "disenchanted elite" as those students who excelled in high school, yet find themselves unprepared for the collegiate environment ${ }^{6}$. Similarly, students report a feeling of being overwhelmed with the engineering curricula, due in large part to the accelerated pace and high workload expected of each engineering course ${ }^{9,10}$. Many also report poor teaching within the SME (science, mathematics, and engineering) curricula ${ }^{10}$. Other curriculum-related factors that discourage engineering students from persevering include restrictive curricula that require strict prerequisite structures, provide limited course offerings, and require additional laboratory work ${ }^{5}$. These curricula restrictions are particularly problematic for non-traditional students. Financial constraints $^{5,9,11}$ are also cited by students as reasons for leaving engineering.

A reported lack of interest in engineering curricula ${ }^{9,10}$ may be indicative of a more specific problem as identified by Edward. He describes a discontinuity based on a student's expectations of an engineering profession and the reality of the degree curriculum. Edward believes that students are sold on a profession which advertises solution of practical problems and hands-on work. However, the reality of engineering education is that it is dominated by highly abstract theory and problems centered on cognitive analysis rather than physical solutions. This disparity between expectation and reality is greatest upon entering an engineering program and lessens throughout the course of study. Edward suggests that those students who leave engineering programs are rejecting engineering curricula rather than engineering professions ${ }^{6}$.

Method

This paper is part of an ongoing study to examine gender parity in undergraduate enrollment in the School of Industrial Engineering at the University of Oklahoma (IE at OU) (award NSFGDSE \#0225228). A semi-structured interview protocol ${ }^{10,13}$ has been used to capture the experiences of undergraduate IE majors from OU. Interviews have been recorded, transcribed professionally, and verified by team members. These data have then been coded using the qualitative analysis software NVivo (URL: http://www.qsrinternational.com/). Data continue to be collected, processed, and analyzed.

Of the 45 students in this portion of the data set, 27 were female $(60 \%)$, 4 were alumni, and 1 was a student who had switched out of IE. This represents a substantial proportion of the IE student body at OU. As of Fall 2001, IE at OU had an undergraduate student body of 84 students with 55\% (47) of the students being female. Women were oversampled by design to maximize the variety of female perspectives represented; men were included to sort out issues that are gender-specific from broader issues. As part of the interview, students were asked to reflect on the various influences that led them to choose IE and the influences that were 
responsible for their persistence in the degree. A search was run on the coded interview transcripts using the search criteria of role models, pre-college influences, choosing IE, and nature of the department. The transcript analysis revealed 106 comments relevant to recruitment and retention. Each comment was first categorized based on whether it addressed recruitment or retention and then sub-categorized according to the specific factor it reflected. This allowed identification of the most influential factors for recruitment and retention, which can be used to inform IE programs desiring increased enrollment and graduation.

\section{Results}

The aggregation of comments reflected 79 comments directed at recruiting, only 27 comments addressed retention. The predominant factors are discussed in the separate contexts of recruiting and retention and student comments are included to most accurately reflect student perceptions. The quotes in this paper have been edited for readability (e.g., many instances of "um" and "you know" have been removed) and identifying information has been replaced with descriptors. When multiple comments from a single student are quoted, this is indicated after the quotation using a subscript on the student descriptor.

The pattern of factors influencing recruitment of students to IE at OU was multi-faceted. Table 1 summarizes the factors that students mentioned as significant in their choice of industrial engineering as a major and presents the number of comments referencing each factor. Table 2 presents a count of the number of students that referenced each factor.

Table 1. Number (percent) of student comments regarding factors important in their choice of industrial engineering.

\begin{tabular}{|rccc|}
\hline Recruiting Factors & $\begin{array}{c}\text { Total \# of Student } \\
\text { Comments }\end{array}$ & $\begin{array}{c}\text { \# of Comments } \\
\text { by Males }\end{array}$ & $\begin{array}{c}\text { \# of Comments } \\
\text { by Females }\end{array}$ \\
\hline Nature of the Degree & 31 & $13(42 \%)$ & $18(58 \%)$ \\
IE Professors/Director & 13 & $3(23 \%)$ & $10(77 \%)$ \\
Recruiting & 9 & $3(33 \%)$ & $6(67 \%)$ \\
Peers & 6 & $4(67 \%)$ & $2(33 \%)$ \\
Family & 5 & $1(20 \%)$ & $4(80 \%)$ \\
HS Recruiter & 3 & $1(33 \%)$ & $2(67 \%)$ \\
SWE & 3 & 0 & $3(100 \%)$ \\
Self Research & 2 & $1(50 \%)$ & $1(50 \%)$ \\
Summer Program & 2 & 0 & $2(100 \%)$ \\
Advisor & 2 & $1(50 \%)$ & $1(50 \%)$ \\
Future & 1 & $1(100 \%)$ & 0 \\
High School Professor & 1 & $1(100 \%)$ & 0 \\
Scholarships & 1 & 0 & $1(100 \%)$ \\
\hline Total & $\mathbf{7 9}$ & $\mathbf{2 9}$ & $\mathbf{5 0}$ \\
\hline
\end{tabular}


Table 2. Number (percent) of students referencing each factor as important in their choice of industrial engineering.

\begin{tabular}{|c|c|c|c|}
\hline Recruiting Factors & $\begin{array}{l}\text { Total \# of } \\
\text { Students* }\end{array}$ & \# of Males & $\begin{array}{c}\text { \# of } \\
\text { Females }\end{array}$ \\
\hline Nature of the Degree & $24(53 \%)$ & $11(46 \%)$ & $13(54 \%)$ \\
\hline IE Professors/Director & $10(22 \%)$ & $3(30 \%)$ & $7(70 \%)$ \\
\hline Recruiting & $9(20 \%)$ & $4(44 \%)$ & $5(56 \%)$ \\
\hline Peers & $6(13 \%)$ & $4(67 \%)$ & $2(33 \%)$ \\
\hline Family & $4(9 \%)$ & $1(25 \%)$ & $3(75 \%)$ \\
\hline HS Recruiter & $3(7 \%)$ & $1(33 \%)$ & $2(67 \%)$ \\
\hline SWE & $3(7 \%)$ & 0 & $3(100 \%)$ \\
\hline Self Research & $2(4 \%)$ & $1(50 \%)$ & $1(50 \%)$ \\
\hline Summer Program & $2(4 \%)$ & 0 & $2(100 \%)$ \\
\hline Advisor & $2(4 \%)$ & $1(50 \%)$ & $1(50 \%)$ \\
\hline $\begin{array}{ll}\text { Future }\end{array}$ & $1(2 \%)$ & $1(100 \%)$ & 0 \\
\hline High School Professor & $1(2 \%)$ & $1(100 \%)$ & 0 \\
\hline Scholarships & $1(2 \%)$ & 0 & $1(100 \%)$ \\
\hline
\end{tabular}

* Percentages are calculated based on the total sample of 45 students.

Several factors played a significant role in the students' choice of industrial engineering as a major. Thirty-nine percent of the comments relevant to recruiting focused on the nature of the degree $^{7}$ as the primary factor responsible for their choice of IE. Fifty-three percent of the students sampled described many different aspects of the degree as appealing: applied, businessoriented, breadth of opportunity, people based, problem solving, and the curriculum. However, a focus was evident on the aspects of the degree related to business. A common theme was that students who were drawn to the business aspects of the IE degree wanted to have a deeper understanding of the problem than a pure business approach would offer.

“... I like the business side more but I really didn't want to do the business major so I wanted to like challenge myself and I like to learn how things work so I chose industrial engineering." (male sophomore)

Other students who were drawn by the business aspects also remarked on the breadth of the discipline as being significant in their decision of major.

“... I chose IE because it seemed like the most broad discipline of engineering. ... So it seemed like a professional degree that combined business and your math and science skills so I really was attracted to it ..." (female senior 1 )

Several students pointed to the opportunity for working with people. One female student, in particular, rejected the derogatory perceptions of IE stated by some of her peers ${ }^{7}$ and stated that IE was a valid engineering discipline but that the approach used by IE was more fun than the other engineering disciplines.

"... I really liked the idea of being able to work with people and it seemed like a more fun approach to engineering but it was still basically engineering ..." (female junior $_{1}$ ) 
IE professors/director was mentioned in $16 \%$ of the comments as having been influential in recruiting the student to IE. These comments came from $22 \%$ of the student sample. This factor was disproportionately mentioned by female students $(77 \%$ of the comments referring to IE professors were made by females). One female student remarked that the efforts of the director had encouraged her to select IE as her major.

"No, he actually called ME..." (female junior)

Another female student was influenced by the amiability of the IE professors with the students.

"I'd met probably five of them [IE professors] just from being with her [sister] going in to turn in papers and stuff like that and they were really nice and really friendly and later I'd see them in the hall and they (would say) 'Oh hi [participant's name] and you know they knew who I was immediately and ... it really made a difference ..." (female junior ${ }_{1}$ )

Eleven percent of the student comments (from $20 \%$ of the students) indicated that specific recruiting activities were influential in their choice of IE. Several students had experienced the formal recruiting presentation sponsored by the OU School of Industrial Engineering. One student who had enrolled in a career's class at the university randomly chose to attend the session on IE. His comments reflect the impact that recruiting can have by informing students who are unaware of the disciple.

"... and one of them that I'd just randomly chosen happened to be industrial engineering, and I realized that that was what I wanted to do. Because that's, I mean that's what I ALWAYS do. I just didn't know there was a degree for it." (male junior ${ }_{1}$ )

Other students mentioned the influence of summer programs and high school activities targeting women in their choice of IE as a major. Several students had family members who are industrial engineers and this too was an important factor in students' decisions to major in IE.

The number of references to retention-related factors was much more limited than the number related to recruitment. In part, this was due to the structure of the interview protocol which directly asked students how they chose IE and who influenced that decision. The protocol questions that may have led to comments on retention were more ambiguous and included probes such as "are you happy with your major", "what interests you most/least", and "would you recommend your major to your friends". Twenty-seven comments were related to student retention in IE. The summary of factors important to student retention is shown in Table 3. Table 4 identifies the number of students from the sample that referenced each retention factor. 
Table 3. Number (percent) of student comments regarding factors important in their ability to persist in industrial engineering.

\begin{tabular}{|rccc|}
\hline Retention Factors & $\begin{array}{c}\text { Total \# of Student } \\
\text { Comments }\end{array}$ & $\begin{array}{c}\text { \# of Comments } \\
\text { by Males }\end{array}$ & $\begin{array}{c}\text { \# of Comments } \\
\text { by Females }\end{array}$ \\
\hline IE Professors/Director & 16 & $7(44 \%)$ & $9(56 \%)$ \\
Department Nature & 7 & $1(14 \%)$ & $6(86 \%)$ \\
Peers & 2 & $1(50 \%)$ & $1(50 \%)$ \\
Advisor & 1 & $1(100 \%)$ & 0 \\
Support & 1 & 0 & $1(100 \%)$ \\
\hline Total & $\mathbf{2 7}$ & $\mathbf{1 0}$ & $\mathbf{1 7}$ \\
\hline
\end{tabular}

Table 4. Number (percent) of students referencing each factor as important in their ability to persist in industrial engineering.

\begin{tabular}{|rccc|}
\hline & Total \# of & & $\begin{array}{c}\text { \# of } \\
\text { Retention Factors }\end{array}$ \\
Students* & \# of Males & Females \\
\hline IE Professors/Director & $13(29 \%)$ & $5(38 \%)$ & $8(62 \%)$ \\
Department Nature & $6(13 \%)$ & $1(17 \%)$ & $5(83 \%)$ \\
Peers & $2(4 \%)$ & $1(50 \%)$ & $1(50 \%)$ \\
Advisor & $1(2 \%)$ & $1(100 \%)$ & 0 \\
Support & $1(2 \%)$ & 0 & $1(100 \%)$ \\
\hline
\end{tabular}

* Percentages are calculated based on the total sample of 45 students.

Retention of students enrolled in IE was strongly influenced by a couple of key factors. It appeared that the faculty in the department had the strongest influence on student retention. Fifty-nine percent of the comments addressed the role of faculty, specifically addressing their availability, encouragement, the level of student interaction, and their influence as role models. However, these comments were received from only $29 \%$ of the student sample. Students reported that faculty who showed an interest in them, who offered advice, and who were more socially engaged with them facilitated their ability to advance through the degree program.

“... as far as faculty members, you can reach them at any time. ... if you need anything at any time you can get a hold of any of them ..." (female sophomore)

“... I almost left here twice ... they didn't push either way or another, but you know, they wanted me to stay, and ... they let me know that. They let me know that they knew who I was ... and that's a big deal." (male junior ${ }_{1}$ )

Other comments pointed to the influence that the director of the School has on retention and recruitment with the devotion of time and attention to undergraduate students.

"... I went for lunch with (IE director). She tells us lots of things about industrial engineering and encourages us to [be] more confident about our choice." (male junior)

The influence of IE faculty as role models was mentioned only by the female students. Five of the sixteen comments directly referenced faculty role models. 
"... I was a scared freshman but just seeing a female in that [IE director] role ... is like a definite role model." (female senior ${ }_{1}$ )

The nature of the department (presence of women faculty and students, congeniality among the faculty and staff) was also influential in retention as evidenced by $26 \%$ of the comments. These comments were reported by only $13 \%$ of the sample but almost exclusively by female students. One IE alumnus perceived this impact on the retention of female students.

“... the IE department is very conscious of the number of women they're bringing into the department ... very proud of it ... they really encouraged it so that when women got into the department, they felt supported and I think they [the female students] stuck (around) maybe more than they would at another school." (female alumnus)

Female students also perceive the IE department at OU as a big family. This factor appears to not only drive retention but to be a source of pride for the female students.

"Family atmosphere definitely." "The way the professors cooperate with each other." (female senior)

"You see us out there all the time for different events which is neat. I think in some ways they might be jealous because we are a little bit better organized than some of the other programs and we are more of a family, it's like we all know each other." (female senior 1 )

In summary, retention of students in the IE program at OU seemed to be most influenced by social factors. This factor may in turn say something about the type of students who are interested in industrial engineering.

\section{Conclusions}

The patterns identified from these student interviews can be used to help recruit students to industrial engineering and to support those students towards achieving graduation. There were some very direct results regarding factors that were influential in recruiting students. It appears to be critical to inform students about industrial engineering, both as a degree option and as a career. Students were very excited about a career in industrial engineering and looked forward to working with people, the business orientation, and the diverse opportunities for professional employment. Students should be exposed to industrial engineering prior to entering college through high school recruiting and summer programs. This finding agrees with previous research findings suggesting students are choosing engineering careers as early as middle school $^{8}$. However, it is important to inform entering college students about industrial engineering because many of the students we interviewed learned about IE after arriving at the university. This can be accomplished with formal recruiting programs that target freshman orientation classes and events. Perhaps an even more important recruiting strategy is direct contact from IE faculty. Many of the students were impressed that IE faculty took the time to 
talk with them about the discipline and were interested enough in the student to establish a more personal relationship. Finally, many of our interviewees were recruited to IE through the influence of their peers. Thus it is critical that recruiting not only be done by faculty but through peer programs as well.

The lessons learned about retention of students in industrial engineering were less programmatic in nature. None of the students specifically addressed an activity or a curriculum-related factor that was responsible for their perseverance. Previous research has reported that a sense of "inclusion" is critical to retaining engineering students ${ }^{14}$. Students in our study perhaps experience this inclusion through interaction with the faculty and the culture that exists within the department. Most important in our study was the faculty-student interaction. Students reported that faculty were always available and showed a genuine interest in the student's academic future. The faculty served as role models and provided important encouragement to the students. The department culture was also critical, particularly to retention of female students. These students expressed a sense of belonging and a perception that the school, as a whole, cared about their success. Unfortunately, these factors are intrinsic to the culture and the faculty personalities in a department. Creating these qualities where they currently do not exist may be difficult at best. However, these findings should be kept in mind when thinking of a department's future. Based on our findings, we recommend that departments strive to build a visible culture of congeniality. We also recommend that departments consider student input when evaluating potential hires and that the candidate's interest in student success be considered as a significant factor in the evaluation. Although it is not essential for all faculty to be involved

to the same degree, retention within industrial engineering is aided by having visible faculty who demonstrate care and concern for the students.

References

[1] National Science Foundation, Division of Science Resources Statistics, Science and Engineering Degrees: 19662000, NSF 02-327, Author, Susan T. Hill (Arlington, VA 2002).

[2] Engineering Trends. Changes in the discipline preferences of undergraduates. Engineering Trends Quarterly Newsletter, Spring 2004. accessed online at http://engtrends.com/news-2004-spring.html on January 1, 2005.

[3] Engineering Workforce Commission. Data for Enrollments. AAES. accessed online at www.ewconline.org/data/enrollments_data.asp on January 1, 2005.

[4] Jackson, S.A. The Quiet Crisis: Falling Short in Producing American Scientific and Technical Talent. San Diego, CA: BEST (Building Engineering \& Science Talent). accessed online at www.bestworkforce.org/PDFdocs/Quiet_Crisis.pdf on January 1, 2005.

[5] National Science Board (2003). The Science and Engineering Workforce: Realizing America's Potential. National Science Foundation, August 14, 2003.

[6] Edward, N.S. (2002). Preaching to the converted. International Journal of Electrical Engineering Education, $39(3)$. 
[7] Trytten, D.A., Shehab, R.L., Rhoads, T.R., Fleener, M.J., Harris, B.J., Reynolds, A., Walden, S.E., MooreFurneaux, S.K, Kvach, E., Warram, K., and Murphy, T.J. (2004). "Inviteful" Engineering: Student Perceptions of Industrial Engineering. Proceedings of the 2004 American Society for Engineering Education Annual Conference and Exposition. Session 3557.

[8] Anderson-Rowland, M.R. (2000). Understanding engineering students for better recruitment strategies: a fouryear study. Proceedings of the $30^{\text {th }}$ ASEE/IEEE Frontiers in Education Conference. Session T2E-19.

[9] Carter, R.L., Hoit, M., and Anderson, T. (2003). Factors influencing freshmen retention in engineering programs. Proceedings of the 2003 American Society for Engineering Education Annual Conference and Exposition. Session 2793.

[10] Seymour, E. \& Hewitt, N. M. (1997). Talking About Leaving: Why Undergraduates Leave the Sciences. Oxford: Westview Press.

[11] Middleton, W. (2002). Electronically tracking and supporting students at risk. International Journal of Electrical Engineering Education, 39(3).

[12] Elton, L. (1991). Motivating students: relations to the world of work. In Gibbs, G. (ed.) Improving Student Learning through Assessment and Evaluation. Oxford Centre for Staff Development, Oxford.

[13] Margolis, J. and A. Fisher (2002). Unlocking the Clubhouse: Women in Computing. Cambridge, Massachusetts: The MIT Press.

[14] Anderson-Rowland, M.R. (2000). Including engineering students. Proceedings of the $30^{\text {th }}$ ASEE/IEEE Frontiers in Education Conference. Session F2F-5.

Author Information

RANDA L SHEHAB is an associate professor in the School of Industrial Engineering at the University of Oklahoma. Her research is in human factors and ergonomics, with emphasis on human performance in occupational environments, physical performance of special populations, technology and learning, and engineering education focusing on recruitment and retention. She can be contacted at rlshehab@ou.edu.

TERI REED RHOADS is associate dean for education of the College of Engineering and assistant professor in the School of Industrial Engineering at the University of Oklahoma. Her research interests include learning in the engineering classroom, web-based learning in statistics, cognitive and affective learning and their assessment, and recruitment and retention focusing on successful students. She can be contacted at teri.rhoads@ou.edu.

TERI J MURPHY is an associate professor in the Department of Mathematics at the University of Oklahoma with research specialty in undergraduate mathematics education. Her primary research interests are in the area of diversity and equity in science, engineering, and mathematics. She can be contacted at tjmurphy@math.ou.edu. 